\title{
BMJ Global Health Oxygen provision to fight COVID-19 in sub-Saharan Africa
}

To cite: Stein F, Perry M, Banda $\mathrm{G}$, et al. Oxygen provision to fight COVID-19 in sub-Saharan Africa. BMJ Global Health 2020;5:e002786. doi:10.1136/ bmjgh-2020-002786

Received 29 April 2020 Revised 6 May 2020 Accepted 8 May 2020

\section{Check for updates}

(c) Author(s) (or their employer(s)) 2020. Re-use permitted under CC BY-NC. No commercial re-use. See rights and permissions. Published by BMJ.

${ }^{1}$ NIHR Global Health Research Unit Tackling Infections to Benefit Africa (TIBA), University of Edinburgh, Edinburgh, UK ${ }^{2}$ Usher Institute, University of Edinburgh, Edinburgh, UK ${ }^{3}$ Regional Infectious Diseases Unit, Western General Hospital, Edinburgh, UK

${ }^{4}$ The Innogen Institute, University of Edinburgh, Science Technology and Innovation Studies, Edinburgh, UK

${ }^{5}$ Institute of Immunology and Infection Research, University of Edinburgh, Edinburgh, UK

Correspondence to

Dr Felix Stein;

felix.stein@ed.ac.uk

\author{
Felix Stein (D) , ${ }^{1,2}$ Meghan Perry, ${ }^{3}$ Geoffrey Banda, ${ }^{1,4}$ Mark Woolhouse, ${ }^{1,2}$ \\ Francisca Mutapi ${ }^{1,5}$
}

\section{INTRODUCTION}

Oxygen saves lives. Its provision is a critical component of emergency respiratory resuscitation around the world, and it consequently features on the WHO's list of essential medicines. ${ }^{1}$ Oxygen therapy is not just used for pneumonia and other lung diseases. It is also crucial for treating various non-respiratory conditions that result in hypoxaemia, such as sepsis, severe malaria, trauma and cardiovascular diseases. It is equally essential for surgical care and anaesthesia.

In Western countries, the reaction to the COVID-19 pandemic has been to increase hospital capacity and to provide more intensive care units (ICUs) and more ventilators. There had been little discussion of the provision of oxygen as this is a standard clinical tool widely available in hospitals. This is not the case in sub-Saharan Africa (SSA). There is a shortage of oxygen in health centres in SSA. ${ }^{2}$ When it comes to prioritising medical resources, SSA needs to save the maximum number of lives during the COVID-19 pandemic; arguably, two things should be atop of that list before ICUs and ventilators. These are personal protective equipment (PPE) for frontline health workers and oxygen for the patients. The need for PPE is a global issue and one whose importance has been highlighted in the different health systems as it is critical to ensure frontline health workers are protected from COVID-19 infection and that they are not infection conduits within hospitals.

Oxygen, on the other hand, has received less attention, and yet it is the second most important aspect of the COVID-19 response. Critically, pneumonia is a predominant clinical feature of COVID-19, and adequate ventilation support is essential for patient survival. It has been indicated that supplemental oxygen is a first essential step for the treatment of patients with severe COVID-19 with hypoxaemia and should be a primary focus in
Summary box

The adequate provision of medical oxygen is going to make the difference between life and death for the majority of patients with COVID-19 in Africa.

- Sub-Saharan African countries lack affordable and reliable oxygen supply.

- There is evidence from sub-Saharan Africa for why medical oxygen provision must be made a regional urgent priority.

- Efforts being made in some African countries demonstrate how oxygen provision can be scaled up through innovative cheap technologies.

resource-limited settings. ${ }^{3}$ In China, a study of 1099 hospitalised patients with laboratoryconfirmed COVID-19 this year found that $41.3 \%$ needed supplemental oxygen and 2.3\% needed invasive mechanical ventilation. ${ }^{4}$ Therefore, investing in supplementary oxygen would strengthen the response to COVID-19 in African countries and save lives.

Prior to the COVID-19 pandemic several countries in SSA were already suffering from shortages of oxygen, shortages of equipment, as well as lack of training to support the correct and optimal use of oxygen therapy ${ }^{5}$ especially for the treatment of paediatric pneumonia. For example, in 2018, only 1 in 10 children with pneumonia in Nigeria received the oxygen they needed. ${ }^{6}$ In Kenya, many rural hospitals lack supplementary oxygen equipment, adequate supply chains for oxygen cylinders and reliable electrical power needed for oxygen delivery. The impact of such shortages during an epidemic were illustrated during the response to influenza. ${ }^{7}$ Even when available, the cost of oxygen in SSA can be prohibitive and prices fluctuate widely, often depending on whether or not production sites are nearby. For example, $6.8 \mathrm{~m}^{3}$ of oxygen (provision for an adult for 24 hours) can reach up to $\$ 100$ in Somalia. ${ }^{8}$ 


\section{NEED FOR OXYGEN TO FIGHT COVID-19 IN SSA}

By modelling the epidemic in each sub-Saharan African country every week (see http://tiba-partnership.org/), we have been able to calculate doubling times for the COVID-19 epidemic, providing important evidence to inform planning and resource mobilisation. We can calculate the oxygen requirements for each country, using the doubling times of diseases spread and the current clinical knowledge available on COVID-19 to calculate a mean oxygen requirement per patient. On the African continent, the COVID-19 pandemic has doubled in size in 10 days up to 16 April. ${ }^{9}$ With only two countries in Africa, Ethiopia $^{10}$ and Nigeria ${ }^{11}{ }^{12}$ having oxygen policy roadmaps, other African countries and their global partners need to put together a rapid plan to supply oxygen to all countries in the region in order to save lives.

Although the majority of people with COVID-19 have uncomplicated or mild illness, WHO currently estimates that around $14 \%$ of cases may be severe and that an additional $5 \%$ will be critical and require treatment in ICUs. ${ }^{13}$ WHO recommends the immediate supply of oxygen therapy as part of clinically managing all patients with severe acute respiratory infection and respiratory distress, hypoxaemia or shock. ${ }^{13}$ Whether or not these patients receive oxygen will be decisive for their survival. It has been observed in the UK that for the hospitalised patients with COVID-19 who require high levels of supplemental oxygen, it is life-saving in approximately $80 \%$ of the cases. ${ }^{14}$ Due to the anticipated large number of people in SSA who will likely require oxygen and the great impact this will likely have on their survival, its provision-together with that of oximeters and oxygendelivering interfaces—should be made a regional priority.

\section{CONTEXT-RELEVANT SOLUTIONS TO OXYGEN SUPPLY}

WHO indicates fewer than 2000 working ventilators exist in 41 African countries to serve hundreds of millions of people in public hospitals, compared with more than 170000 in the USA. ${ }^{15}$ Ten countries in Africa have no ventilators at all. ${ }^{15}$ Ventilators are not going to be the solution for the majority of patients with COVID-19 in Africa for two reasons. First, only a small number $(<3 \%)$ of patients with COVID-19 need ventilators. ${ }^{4}$ Second, if there is no oxygen to put in the ventilators, they cannot be used. Allocating resources to widespread oxygen provision will save more lives.

Medical oxygen is a regulated commodity that must be at least $82 \%$ pure, free from any contamination and generated by an oil-free compressor. ${ }^{16}$ It can come from oxygen plants, liquid oxygen storage tanks or oxygen concentrators. In SSA, there are two main sources of oxygen: concentrators and cylinders (see table 1). While concentrators are the cheapest and most scalable way to supply oxygen, they require a functioning infrastructure with reliable power supply (although some countries have solved this problem by using solar-powered concentrators as detailed further), as well as regular servicing. In addition, the level of oxygen flow that they can deliver (usually between 5 and $10 \mathrm{~L} / \mathrm{min}$ ) can also be insufficient for severe patients requiring $15 \mathrm{~L} / \mathrm{min}$, yet they may be used to ease demand on cylinders, which can be directed to patients with severe COVID-19. The more expensive cylinders require neither a power source nor costly maintenance. Clinicians in some SSA health systems have indicated that the priority list would include first pulse oximeters to measure oxygen levels, followed by oxygen concentrators that can be used in small healthcare settings and finally higher-tech equipment like ventilators.

\section{SOME SOLUTIONS FROM AFRICAN COUNTRIES FOR BUILDING OXYGEN SUPPLY}

The problem is not insurmountable. Home-grown innovation is allowing some African countries to address the oxygen supply challenges. For example, a 42-bed hospital in the Gambia has managed to ensure uninterrupted oxygen supply for 8 years straight, using oxygen concentrators (rather than the more expensive cylinders) ${ }^{17}$ In Kenya, a county government enabled the construction of an oxygen plant by a private company, while the hospital commissioning the plant committed

\begin{tabular}{|c|c|c|}
\hline & Oxygen cylinders & Oxygen concentrators \\
\hline Capital cost & $\begin{array}{l}\text { Low (higher if including regulators and flow-meter } \\
\text { assemblies) }\end{array}$ & Moderate \\
\hline Running cost & High: frequent refilling, transport and logistics & Low: power, maintenance \\
\hline Power source & None required & Required, continuously \\
\hline Reliability & Good, so long as supply lasts & Good, on selected models \\
\hline Continuous supply & $\begin{array}{l}\text { No, limited by volume (large } \mathrm{H} \text {-type cylinders last } 2-4 \\
\text { days with continuous low-flow use) }\end{array}$ & Yes, limited by equipment or power failure \\
\hline Maintenance & Minimal: check regulators, leakage & $\begin{array}{l}\text { Essential: simple preventive and intermittent } \\
\text { repairs }\end{array}$ \\
\hline Training & $\begin{array}{l}\text { Yes, clinical use of oxygen, care of cylinders and } \\
\text { connections }\end{array}$ & $\begin{array}{l}\text { Yes, clinical use of oxygen, care of } \\
\text { concentrators and connections, technical } \\
\text { maintenance }\end{array}$ \\
\hline
\end{tabular}


in advanced to buying a fixed oxygen quota. ${ }^{18}$ In Ethiopia, a garment manufacturer that produces oxygen for bleaching purposes aims to provide it to a nearby hospital, reflecting technology spillover. ${ }^{15}$ In Uganda, solar-powered oxygen delivery for rural settings has been developed to overcome issues of unreliable power supply. ${ }^{19}$ Solar-powered systems can turn ambient air into medical-grade oxygen with battery banks, enabling uninterrupted service through the night and on cloudy days. Provided they come with 'roadmaps' for local procurement, training and maintenance, they can be used in offgrid settings. ${ }^{20}$ To deal with the shortage of ventilators, Senegal is pioneering the use of 3-D printed ventilators costing US $\$ 60 .^{21}$ These initiatives clearly demonstrate the successes of partnerships between governments, the private sector and hospitals to urgently increase regional oxygen availability. Development partners should be prioritising support for these local initiatives whose longterm impact and health legacy will outlast the COVID-19 pandemic.

\section{CONCLUSION}

The recovery of critically ill patients with COVID-19 will require oxygen. Available evidence supports prioritising investment in oxygen infrastructure, not only for COVID-19 and severe acute respiratory infections but also for other conditions that cause hypoxaemia. African countries should develop oxygen roadmaps that prioritise procurement of equipment, such as oxygen concentrators or high-pressure cylinders and oxygen from local industry. Examples from African countries demonstrate that oxygen provision can be scaled up through innovative cheap technologies. Responses by development partners and funders for local, context-specific solutions to the region's oxygen supply shortages are encouraging. They need to be accelerated.

Acknowledgements We are grateful to Professor Tom Evans from the University of Glasgow for reviewing an earlier draft of this manuscript. This work was commissioned by the National Institute for Health Research (NIHR) Global Health Research programme (16/136/33) using UK aid from the UK Government. The views expressed in this publication are those of the authors and not necessarily those of the NIHR or the Department of Health and Social Care.

Contributors FM has conceived of the work and substantially contributed to its writing and analysis. FS has substantially contributed to its writing and analysis. MW, GB and MP have substantially contributed to the analysis. All five authors have drafted and revised the text. They all have provided final approval of the version to be published and agreed to be accountable for all aspects of the work with respect to its accuracy and research integrity.

Funding The authors have not declared a specific grant for this research from any funding agency in the public, commercial or not-for-profit sectors.

Competing interests None declared.

Patient consent for publication Not required.

Provenance and peer review Not commissioned; externally peer reviewed.

Data availability statement No additional data are available.

Open access This is an open access article distributed in accordance with the Creative Commons Attribution Non Commercial (CC BY-NC 4.0) license, which permits others to distribute, remix, adapt, build upon this work non-commercially, and license their derivative works on different terms, provided the original work is properly cited, appropriate credit is given, any changes made indicated, and the use is non-commercial. See: http://creativecommons.org/licenses/by-nc/4.0/.

Author note TIBA twitter handle @TibaPartnership

ORCID iD

Felix Stein http://orcid.org/0000-0002-0123-9895

\section{REFERENCES}

1 WHO (World Health Organisation). WHO model list of essential medicines, 2017. Available: https://www.who.int/medicines/ publications/essentialmedicines/en

2 Belle J, Cohen H, Shindo N, et al. Influenza preparedness in lowresource settings: a look at oxygen delivery in 12 African countries. $J$ Infect Dev Ctries 2010;4:419-24.

3 Dondorp AM, Hayat M, Aryal D, et al. Respiratory support in novel coronavirus disease (COVID-19) patients, with a focus on resourcelimited settings. Am J Trop Med Hyg 2020:1-7.

4 Guan W-J, Ni Z-Y, Hu Y, et al. Clinical characteristics of coronavirus disease 2019 in China. N Engl J Med 2020;382:1708-20.

5 Dauncey JW, Olupot-Olupot P, Maitland K. Healthcare-provider perceptions of barriers to oxygen therapy for paediatric patients in three government-funded eastern Ugandan hospitals; a qualitative study. BMC Health Serv Res 2019;19:335.

6 Macnamara K. "'Suffering, gasping': experts warn of oxygen shortages in poorer virus-threatened nations", 2020. Available: https://www.barrons.com/news/suffering-gasping-experts-warn-ofoxygen-shortages-in-poorer-virus-threatened-nations-01587527706

7 International Vaccine Access Center, Johns Hopkins Bloomberg School of Public Health. Pneumonia \& diarrhea progress report 2018, 2020. Available: https://stoppneumonia.org/wp-content/ uploads/2018/11/Pneumonia-and-Diarrhea-Progress-Report-2018. pdf

8 Zhu A. Coronavirus exposes Africa's oxygen problem, 2020. Available: https://www.thenewhumanitarian.org/news/2020/04/16/ Africa-oxygen-problem-coronavirus

9 TIBA. Based on TIBA Covid-19 situation report for WHO African region analysis. Available: http://tiba-partnership.org/

10 Ministry of Health of The Federal Democratic Republic of Ethiopia. National medical oxygen and pulse oximetry scale up road map, 2016. Available: http://196.189.110.22/bitstream/ handle/123456789/670/1.\%20National\%20Medical\%200xygen\% 20 and $\% 20$ Pulse $\% 20$ Oximetry $\% 20$ Scale $\% 20$ Up $\% 20$ Road\% 20Map\%20\%282016-2021\%29\%20\%282\%29.pdf? sequence $=1 \&$ isAllowed $=\mathrm{y}$,

11 Federal Ministry of Health of the Federal Republic of Nigeria. National strategy for the scale-up of medical oxygen in health facilities 2017 - 2022, 2017. Available: https://www.medbox.org/ document/national-strategy-for-the-scale-up-of-medical-oxygen-inhealth-facilities-2017-2022\#GO

12 Federal Ministry of Health of the Federal Republic of Nigeria. National policy on medical oxygen in health facilities. Abuja, 2017.

13 WHO (World Health Organisation). Clinical management of severe acute respiratory infection (Sari) when COVID-19 disease is suspected (interim guidance, 13 March 2020), 2020. Available: https://www.who.int/docs/default-source/coronaviruse/clinicalmanagement-of-novel-cov.pdf

14 Numbers based on personal communication with Infectious Diseases specialists from NHS Scotland.

15 Maclean R, Simon M. 10 African countries have no ventilators. That's only part of the problem, 2020. Available: https://www.nytimes.com/ 2020/04/18/world/africa/africa-coronavirus-ventilators.html

16 WHO (World Health Organization). Oxygen sources and distribution for Covid-19 treatment centres (interim guidance 4 April 2020), 2020. Available: https://www.who.int/publications-detail/oxygen-sourcesand-distribution-for-covid-19-treatment-centres

17 Bradley BD, Light JD, Ebonyi AO, et al. Implementation and 8-year follow-up of an uninterrupted oxygen supply system in a hospital in the Gambia. Int J Tuberc Lung Dis 2016;20:1130-4.

18 News T. Opinion: government should change tact on medical oxygen, 2020. Available: https://www.tuko.co.ke/351679-opiniongovernment-change-tact-medical-oxygen.html

19 Conradi N, Mian Q, Namasopo S, et al. Solar-powered oxygen delivery for the treatment of children with hypoxemia: protocol for a cluster-randomized stepped-wedge controlled trial in Uganda. Trials 2019;20:679. 
20 Canada GC. Innovators mobilize to help developing countries combat Covid-19, 2020. Available: https://www.grandchallenges.ca/2020/ innovators-mobilize-to-help-developing-countries-combat-covid-19/

21 Sylvester T. Senegal develops \$1 test kits, \$60 3d printed ventilators to help fight against coronavirus, 2020. Available: https://www. kanyidaily.com/2020/04/senegal-develops-1-test-kits-60-3d-printedventilators-to-fight-against-novel-coronavirus.htm

22 Graham HR, Ayede Al, Bakare AA, et al. Oxygen for children and newborns in non-tertiary hospitals in south-west Nigeria: a needs assessment. Afr J Med Med Sci 2016;45:45. 